\title{
p21-activated kinase group II small compound inhibitor GNE- 2861 perturbs estrogen receptor alpha signaling and restores tamoxifen-sensitivity in breast cancer cells
}

\author{
Ting Zhuang ${ }^{1, *}$, Jian Zhu ${ }^{1, *}$, Zhilun $\mathbf{L i}^{1}$, Julie Lorent ${ }^{2}$, Chunyan Zhao ${ }^{1}$, \\ Karin DahIman-Wright ${ }^{1,3}$, Staffan Strömblad ${ }^{1}$ \\ ${ }^{1}$ Department of Biosciences and Nutrition, Novum, Karolinska Institutet, Huddinge, Sweden \\ ${ }^{2}$ Department of Oncology and Pathology, Karolinska Institutet, Solna, Sweden \\ ${ }^{3}$ Science for Life Laboratory (SciLifeLab), Karolinska Institutet, Solna, Sweden \\ * These authors have contributed equally to this work. \\ Correspondence to: Staffan Strömblad, e-mail: staffan.stromblad@ki.se
}

Keywords: PAK4, ERa, tamoxifen resistance, phosphorylation, small molecule inhibitor

Received: July 07, $2015 \quad$ Accepted: October 26, $2015 \quad$ Published: November 06, 2015

\section{ABSTRACT}

Estrogen receptor alpha (ERa) is highly expressed in most breast cancers. Consequently, ERa modulators, such as tamoxifen, are successful in breast cancer treatment, although tamoxifen resistance is commonly observed. While tamoxifen resistance may be caused by altered ERa signaling, the molecular mechanisms regulating ERa signaling and tamoxifen resistance are not entirely clear. Here, we found that PAK4 expression was consistently correlated to poor patient outcome in endocrine treated and tamoxifen-only treated breast cancer patients. Importantly, while PAK4 overexpression promoted tamoxifen resistance in MCF-7 human breast cancer cells, pharmacological treatment with a group II PAK (PAK4, 5, 6) inhibitor, GNE-2861, sensitized tamoxifen resistant MCF-7/LCC2 breast cancer cells to tamoxifen. Mechanistically, we identified a regulatory positive feedback loop, where ERa bound to the PAK4 gene, thereby promoting PAK4 expression, while PAK4 in turn stabilized the ERa protein, activated ERa transcriptional activity and ERa target gene expression. Further, PAK4 phosphorylated ERa-Ser305, a phosphorylation event needed for the PAK4 activation of ERa-dependent transcription. In conclusion, PAK4 may be a suitable target for perturbing ERa signaling and tamoxifen resistance in breast cancer patients.

\section{INTRODUCTION}

Breast cancer is the most common cancer worldwide and the second most frequent cancer mortality in females [1]. $70 \%$ of all breast cancers are estrogen receptor $\alpha$ $(\mathrm{ER} \alpha)$ positive, where $\mathrm{ER} \alpha$ constitutes a driving force for breast cancer progression [2]. ER $\alpha$ exerts its functions through binding to estrogen responsive elements (EREs) or by indirect binding to DNA through other transcription factors, which subsequently induces the expression of target genes [3]. ER $\alpha$ positive breast cancer patients often benefit from ER $\alpha$ antagonist treatment. As such, tamoxifen is the most commonly used ER $\alpha$ antagonist in the clinic. Although tamoxifen largely improves breast cancer patient survival, the development of tamoxifen-resistance is common. Several mechanisms could contribute to tamoxifen resistance, including alterations in estrogen signaling and/or crosstalk between estrogen signaling and growth factor signaling pathways $[4,5]$. In particular, post-translational modifications of ER $\alpha$, such as phosphorylations, may play important roles in regulating estrogen signaling thereby overcoming tamoxifen responsiveness [6].

The PAK (p21-activated kinase) family are serine/ threonine kinases acting downstream of the small GTPases Cdc42 and Rac with regulatory roles of cytoskeletal dynamics [7]. PAKs are classified into Group I (PAK1-3) and Group II (PAK4-6) based on sequence homology, although all PAKs have an N-terminal GTPase (Rac/ Cdc42)-binding regulatory domain and a C-terminal kinase domain [8]. Interestingly, PAKs may play functional roles in several oncogenic events, including 
oncogenic transformation, invasion and metastasis [8]. However, the different PAK family kinases may exert different or even opposite effects. In fact, this appears to be the case in ER $\alpha$ signaling, where PAK1 and PAK6 may regulate $\mathrm{ER} \alpha$ signaling in opposite directions. While immunohistochemical staining of PAK1 in breast cancer patient specimens was correlated to tamoxifen resistance $[9,10]$, possibly related to PAK1-mediated phosphorylation of ER $\alpha$ [11-14], PAK6 binds ER $\alpha$ and inhibits its transcriptional activity, and this PAK6ER $\alpha$ interaction could be enhanced by tamoxifen [15]. Nevertheless, the possible mechanistic involvement of PAK kinases in tamoxifen resistance remains unclear.

Interestingly, a number of findings suggest that PAK4 may be involved in cancer progression [16]. For example, PAK4 is up-regulated in most human cancer cell lines [17], and has also been found to be overexpressed in patient material of several human cancer forms, including colon, esophageal, pancreas, ovarian cancer, and breast cancer [18-21]. Importantly, high PAK4 expression in ovary cancer was correlated with progressing disease stage, poor patient survival and to resistance to chemotherapy [19]. Functionally, PAK4 may play a role in transformation, since dominant-negative PAK4 partially inhibited Ras-induced transformation in NIH3T3 mouse embryonic fibroblasts; a constitutively active PAK4 mutant transformed NIH3T3 cells in vitro [17,22]; and overexpression of either activated or wild-type PAK4 made NIH3T3 cells tumorigenic in athymic mice in vivo [21]. PAK4 may also be required for anchorage-independent growth of NIH3T3 cells and HCT116 human colon carcinoma cells [17, 22]. In breast cancer cells, PAK4 inhibits cell adhesion [22-24] and promotes cell migration by selectively inducing $\alpha v \beta 5$ mediated breast cancer cell motility through the phosphorylation of the integrin $\beta 5$ cytoplasmic tail and by regulating actin depolymerisation through phosphorylation of LIMK1 [24-28]. Moreover, PAK4 may also protect mouse fibroblasts and HeLa cells from apoptosis by phosphorylating $\mathrm{BAD}$, a potentially tumor promoting effect [29]. However, the potential role of PAK4 in breast cancer remains largely elusive, for example whether PAK4 may directly affect breast cancer related proteins such as ER $\alpha$.

At the same time, there is an urgent need to find ways to overcome tamoxifen resistance in the clinic, including the identification of targets affecting the tamoxifen response. To this end, the recent development of different PAK inhibitors now facilitates the testing of their suitability for treatment of breast cancer [30-32]. However, it is unclear which PAKs may be suitable targets to overcome tamoxifen resistance.

Here, using two distinct gene expression databases, each containing information from more than 1900 breast cancer patients, we found that high PAK4 expression consistently correlated with poor outcome for endocrine treatment and specifically tamoxifen treated breast cancer patients, while the expression of other PAK family members did not consistently display such correlation in both databases. Mechanistically, we discovered a novel positive feedback loop between ER $\alpha$ and PAK4, where ER $\alpha$ binds to the PAK4 gene and induces the expression of PAK4, and where PAK4 in turn phosphorylates ER $\alpha$, promotes ER $\alpha$ protein stability and its transcriptional activity. Importantly, while overexpression of PAK4 caused decreased sensitivity to tamoxifen in MCF7 human breast cancer cells, a specific inhibitor of group II PAKs, GNE-2861, restored the sensitivity to tamoxifen in the tamoxifen-resistant MCF-7/LCC2 cells. Taken together, PAK4 appears as an interesting target to explore for the restoration of tamoxifen sensitivity in breast cancer.

\section{RESULTS}

\section{Association between PAK4 gene expression and clinical outcome among tamoxifen treated breast cancer patients}

The potential prognostic role of PAK family members in endocrine therapy-treated patients was explored in two large public breast cancer datasets, Metabric and KMplot [33, 34], where we assessed two related end-points, disease-free survival and relapse-free survival, respectively, since identical endpoints were not available. We found that high PAK4 expression was associated with poor disease-specific survival among the 915 Metabric ER $\alpha$ positive endocrine therapytreated patients in a univariable model (Figure 1A, HR $=1.34 ; 95 \%$ CI: $1.03-1.74)$. In the Metabric database, while endocrine treated patients can be identified, no information is available in terms of the specific endocrine treatment. However, in the KMplot breast cancer database, we were able to analyze a tamoxifen-only treated patient group. In the selected KMplot populations of 725 ER $\alpha$ positive patients treated only with endocrine therapy as systemic adjuvant treatment ("endocrine therapy only"), high PAK4 expression was also associated with poor prognosis (Figure 1B, HR $=1.55$; 95\% CI: 1.15-2.08). Most patients in the endocrine treated group received tamoxifen. Importantly, also among cases with tamoxifen as the only systemic adjuvant treatment ("tamoxifenonly") ( $n=650)$, high PAK4 expression was correlated to poor relapse-free survival (Figure 1C, HR $=1.79 ; 95 \%$ CI: $1.20-2.67)$ in a univariable model for relapse-free survival. The patient outcome in tamoxifen-only treated group in relation to PAK4 expression was consistent with that of the endocrine treated patients in both the Metabric and the KMplot datasets. However, while high PAK2 and PAK6 expression correlated with relapse-free survival in the KMplot dataset, no such correlation was detectable in the Metabric dataset (Supplementary Figure S1 and S2). Thus, no consistent correlation was detected between the expression of PAK family members other than PAK4 
(PAK1, 2, 3, 5, 6) and the patient outcome of endocrine treated breast cancer patients in the two databases.

The correlation between high PAK4 expression and unfavorable endocrine treated breast cancer patient outcome is consistent with a potential role for PAK4 in tamoxifen resistance. This motivated us to further examine such a potential role for PAK4.

\section{Pharmacological targeting of group II PAKs restores tamoxifen sensititvity in human breast cancer cells}

Based on the prognostic role of PAK4 in endocrine treated and tamoxifen-only treated breast cancer patients, we examined if PAK4 may affect the tamoxifen response in human breast cancer cells. As shown in Figure 2A, stable overexpression of PAK4 significantly decreased the tamoxifen sensitivity in human MCF-7 breast cancer cells (Figure 2A). It can be noted that low concentration of tamoxifen promoted cell proliferation, consistent with the well-established estrogen-like effect of low tamoxifen concentrations [35]. Interestingly, a recently developed small organic compound, GNE-2861 (Compound 17), specifically inhibits group II PAKs (PAK4, 5, 6), but not group I PAKs (PAK1, 2, 3) [31], thereby facilitating pharmacological targeting of group II PAKs in cells. We selected this inhibitor because it displays the most impressive specificity profile among known PAK4-inhibitors [30, 31, 36]. Importantly, GNE2861 enhanced the tamoxifen sensitivity in MCF-7 cells (Figure 2B), as well as in the tamoxifen-resistant human breast cancer cell line MCF-7/LCC2 [37, 38] where GNE-2861 restored the tamoxifen sensitivity to a similar level as in untreated tamoxifen-sensitive MCF7 maternal cells (Figure 2B-2C). As shown in Figure 2B-2C, the approximate IC50 of tamoxifen in MCF-7/ Control and MCF7/LCC2 cells are $7 \mu \mathrm{M}$ and $14 \mu \mathrm{M}$, respectively. By keeping the tamoxifen concentration constant at the approximate IC50 for each cell line and varying the concentration of GNE-2861, we found that tamoxifen sensitized breast cancer cells to GNE-2861 treatment (Figure 2D-2E). Together, this indicates that PAK4 contributes to tamoxifen resistance in breast cancer cells and may be used as a target to restore tamoxifen sensitivity. Further, this indicates that the group II PAK inhibitor GNE-2861 may be a candidate for the development of tamoxifen-sensitizing pharmacological treatment.

\section{PAK4 is a direct ERa target gene}

The clinical correlation between PAK4 and endocrine treated breast cancer patient outcome together with the functional role of PAK4 in tamoxifen response suggest that there may be a regulatory relationship between PAK4 and ER $\alpha$. To elucidate this potential relationship, we treated $\mathrm{MCF}-7$ cells with $10 \mathrm{nM} 17 \beta$-estradiol (E2), a natural ligand of $\mathrm{ER} \alpha$. Interestingly, E2 treatment increased both PAK 4 mRNA and protein levels in a time dependent manner (Figure 3A and 3B). Also, our results (Figure 3B) are consistent with the well-known phenomena that E2 treatment significantly reduces ER $\alpha$ protein levels [39]. In addition, analysis of the ER $\alpha$ genomic
A

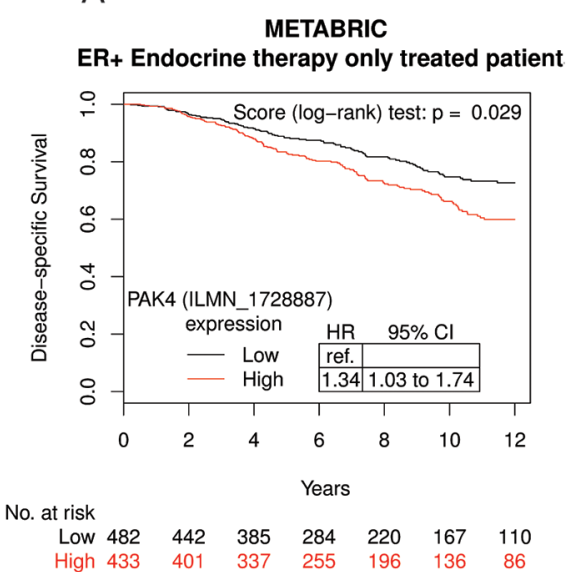

B KMPLOT
ER+ Endocrine therapy only treated patient

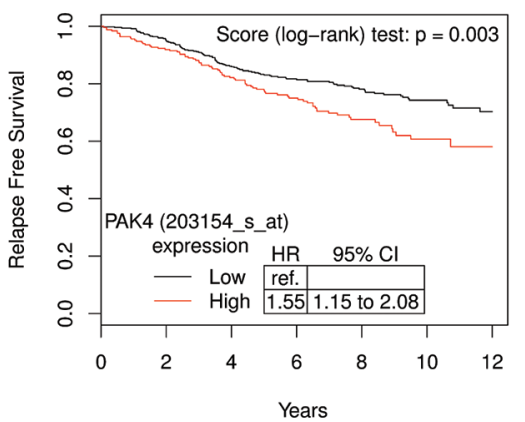

No. at risk

$\begin{array}{lllllll}\text { Low } 475 & 442 & 373 & 282 & 218 & 114 & 48\end{array}$
C KMPLOT ER+ Tamoxifen only treated patients

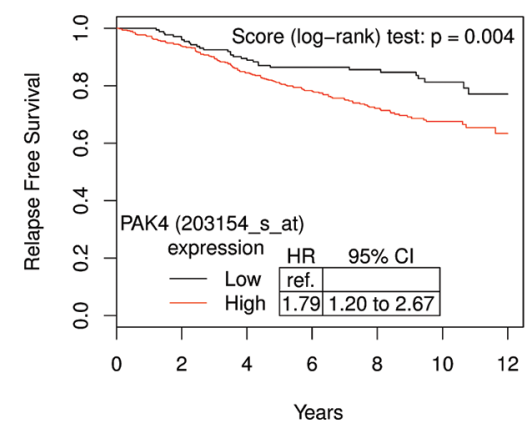

No. at risk

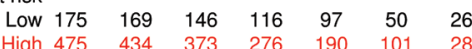

Figure 1: High PAK4 mRNA expression levels correlate with poor survival of endocrine-treated breast cancer patients. A. Kaplan-Meier plot of disease-specific survival in ER+, endocrine therapy only treated patients in the Metabric database stratified for high (red) and low (black) PAK4 expression levels ( $n=915$; median cut-off; Probe ILMN_1728887: HR=1.34; 95\% CI: 1.03$1.74 ; P=0.029)$. B. Kaplan-Meier plot showing that high PAK4 expression correlates with relapse free survival in ER+, endocrine therapy only treated patients in the KMplot database stratified for high (red) and low (black) PAK4 expression levels ( $n=725$; optimized cut-off; Probe 203154_s_at: $\mathrm{H} R=1.55 ; 95 \%$ CI: 1.15-2.08; $P=0.003)$. C. Kaplan-Meier plot showing that high PAK4 expression correlates with relapse free survival in ER+, tamoxifen-only treated patients in the KMplot database stratified for high (red) and low (black) PAK4 expression levels ( $n=650$; optimized cut-off; Probe 203154_s_at: $\mathrm{H} R=1.79 ; 95 \% \mathrm{CI}: 1.20-2.67 ; P=0.004)$. 
A

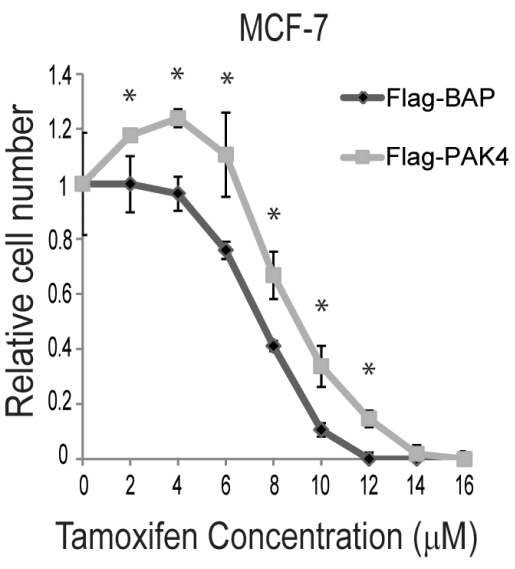

B

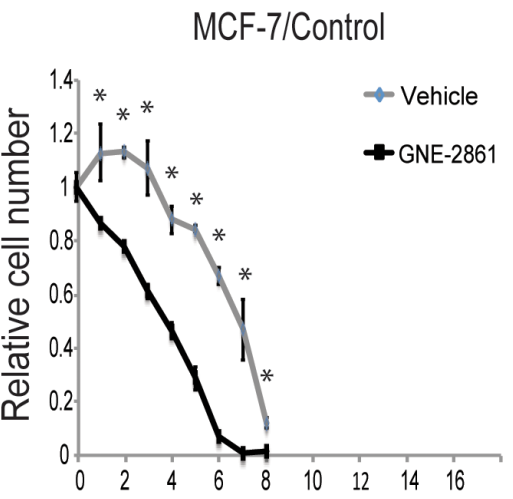

C

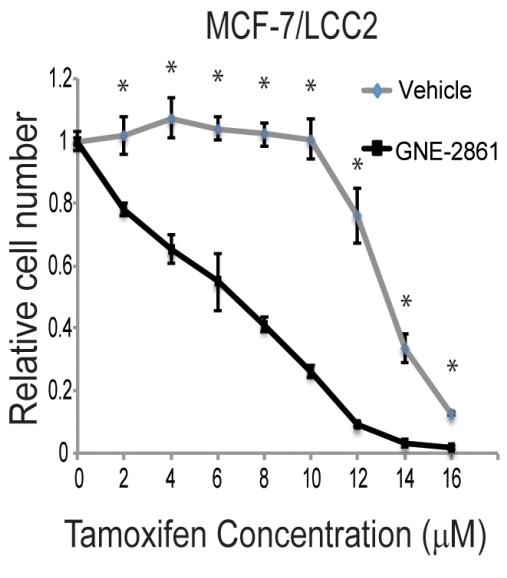

D

Tamoxifen Concentration $(\mu \mathrm{M})$

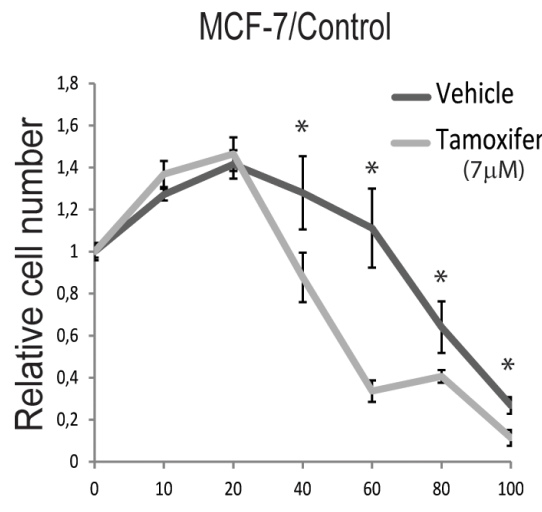

GNE-2861 Concentration ( $\mu \mathrm{M})$

$E$

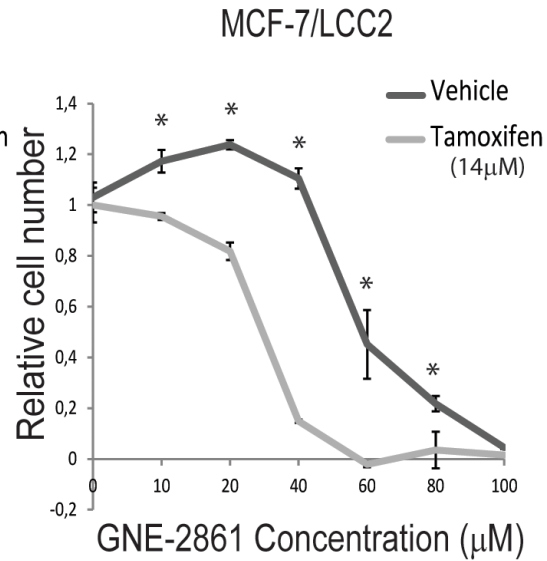

Figure 2: The group II PAK inhibitor GNE-2861 restores tamoxifen-sensitivity in breast cancer cells. A. PAK4 overexpression inhibits the tamoxifen-response in MCF-7 ER $\alpha$ positive human breast cancer cells. MCF-7 cells with stable transfection of Flag-PAK4 or Flag-BAP control were treated with the indicated tamoxifen concentrations for $48 \mathrm{~h}$ and the number of cells was quantified by a WST-1 assay. Shown values represent mean \pm s.d. $(\mathrm{n}=3)$ for each concentration, representative for three independent experiments. *- $P<0.05$ compared to control, according to $t$-test. B-C. The group II PAK inhibitor GNE-2861 sensitizes breast cancer cells to tamoxifen treatment. B) MCF-7/Control cells and C) MCF-7/LCC2 tamoxifen resistant cells were treated with vehicle or $50 \mu \mathrm{M}$ GNE-2861. In addition, each group of cells was treated with the indicated concentrations of tamoxifen for $48 \mathrm{~h}$ and the number of cells was quantified by a WST-1 assay. Shown values represent mean \pm s.d. $(\mathrm{n}=3)$ for each concentration, representative for three independent experiments. ${ }^{*} P$ $<0.05$ compared to control, according to $t$-test. D-E. Tamoxifen sensitizes breast cancer cells to GNE-2861 treatment. D) MCF-7/Control cells were treated with vehicle or $7 \mu \mathrm{M}$ tamoxifen. E) MCF-7/LCC2 tamoxifen resistant cells were treated with vehicle or $14 \mu \mathrm{M}$ tamoxifen. In addition, each group of cells was treated with the indicated concentrations of GNE-2861 for $48 \mathrm{~h}$ and the number of cells was quantified by a WST-1 assay. Shown values represent mean \pm s.d. $(\mathrm{n}=3)$ for each concentration, based on three independent experiments. ${ }^{*}-P<0.05$ compared to control, according to $t$-test. 
A

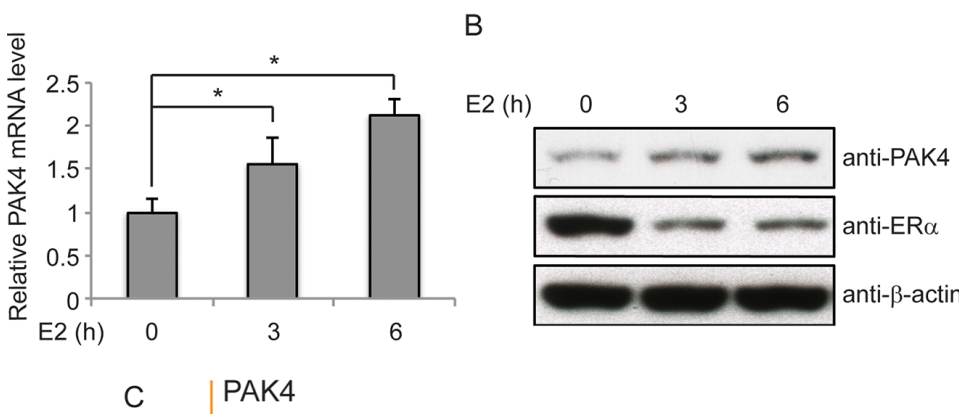

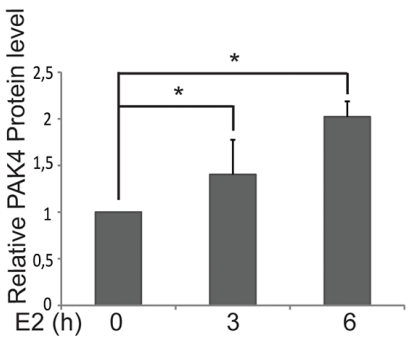

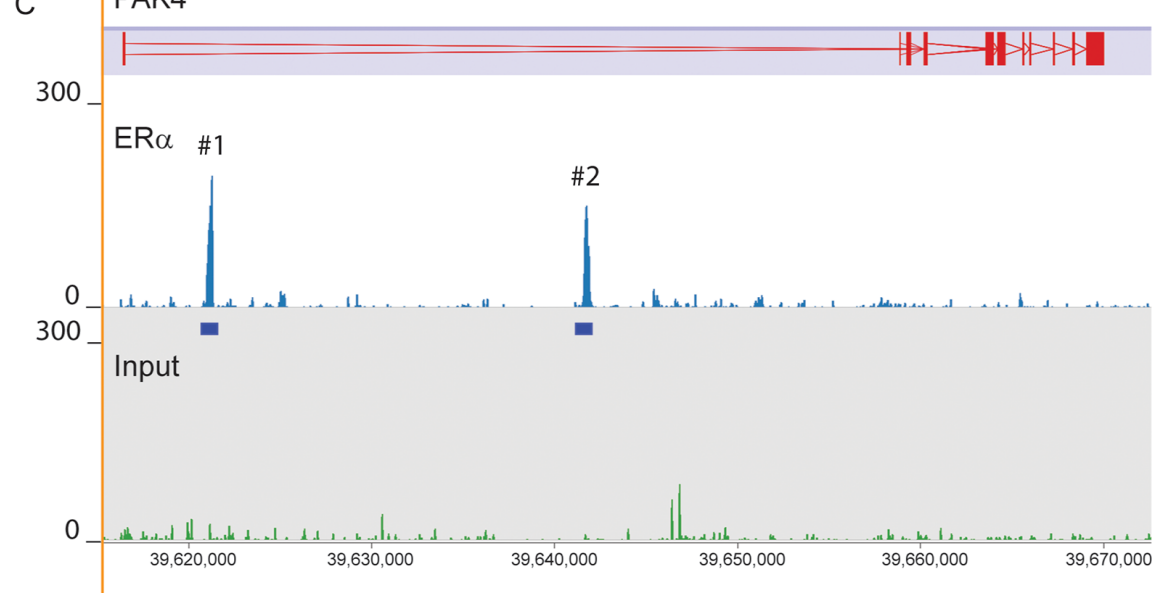

$\mathrm{D}$

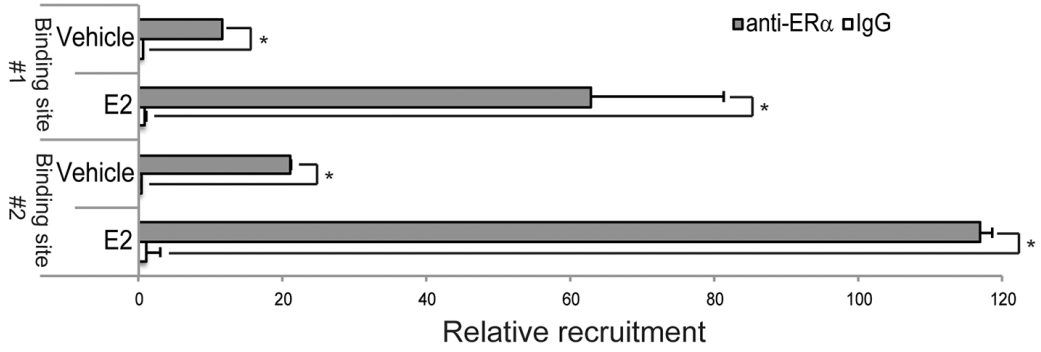

$\mathrm{E}$

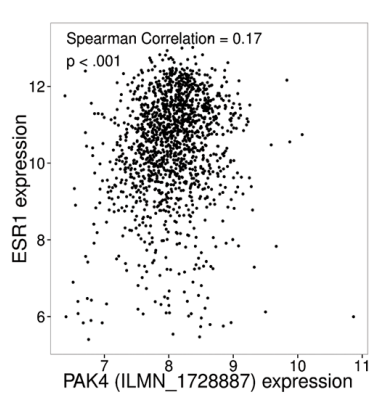

$\mathrm{F}$

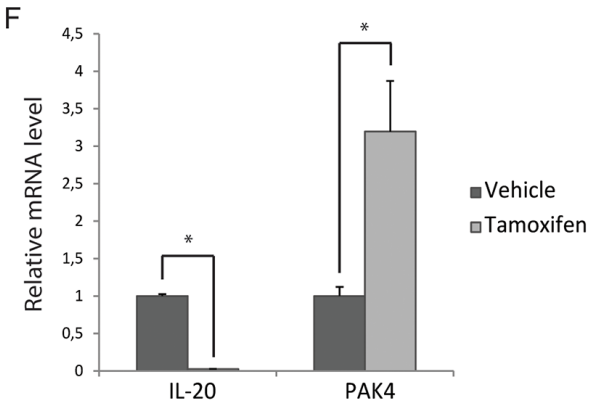

Figure 3: ER $\boldsymbol{\alpha}$ binds to the PAK4 gene and promotes PAK4 expression. A-B. Induction of PAK4 mRNA and protein by E2. Serum-starved MCF-7 cells were treated with10 nM E2 for up to $6 \mathrm{~h}$. A) The levels of PAK4 mRNA were assessed by qPCR, using 36B4 as an internal control. B) Left: The protein levels were determined by immunoblotting, using $\beta$-actin as a loading control. Right: Quantification of PAK4 signal in the immunoblot. Shown values represent mean \pm s.d. $(\mathrm{n}=3)$. ${ }^{*}-P<0.05$ compared to control, according to $t$-test. C. ChIP-seq results show the ER $\alpha$ binding peaks within the PAK4 gene locus after E2 treatment. The PAK4 gene is represented in the top track. ER $\alpha$ ChIP-seq signal is shown in the middle track and input ChIP-seq signal in the bottom track. D. ChIP-qPCR analysis confirms the recruitment of ER $\alpha$ to the two regions of the PAK4 gene indicated in C. Data presented are normalized to input DNA and expressed as fold enrichment over IgG. Shown values are mean \pm s.d. $(\mathrm{n}=3){ }^{*}-P<0.05$ as compared with IgG controls, according to $t$-test. E. Positive correlation between ESR1 and PAK4 (probe ILMN_1728887) gene expression in ER+ breast cancer patients in the Metabric database ( $n$ $=1394$ ). Spearman correlation $=0.17 ; P<0.001$. F. Tamoxifen regulation of PAK4 mRNA levels. MCF-7 cells were treated with $1 \mu \mathrm{M}$ tamoxifen for $12 \mathrm{~h}$. The relative IL-20 (positive control for tamoxifen effect) and PAK4 mRNA levels were assessed by qPCR, using 36B4 as an internal control. Shown values represent mean \pm s.d. $(\mathrm{n}=3){ }^{*}-P<0.05$ compared to control, according to $t$-test. 
DNA-binding profile in MCF-7 cells by chromatin immunoprecipitation followed by sequencing (ChIPseq) revealed two $\mathrm{ER} \alpha$ binding sites within intron 1 of the PAK4 gene (Figure 3C). The data have been deposited in NCBI's Gene Expression Omnibus (Zhuang et al., 2015) and are accessible through GEO Series accession number GSE73320 (http://www.ncbi.nlm. nih.gov/geo/query/acc.cgi?acc=GSE73320). These two binding sites were also observed in other published ER $\alpha$ cistromes $[40,41]$ and one of the binding sites was also found to be present in the ER $\alpha$ cistrome of 1,234 binding sites identified by Lin and colleagues [42]. Chromatin immunoprecipitation followed by quantitative PCR (ChIP-qPCR) validated the binding of ER $\alpha$ to these two regions (Figure 3D), an interaction that was increased by E2 treatment. Together, this indicates a regulatory role for ER $\alpha$ signaling on PAK4 expression via direct ER $\alpha$ binding to the PAK4 gene. Interestingly, analysis of data from ER+ breast cancer patients in the Metabric database shows a positive correlation between ESR 1 and PAK4 gene expression (Figure 3E), which is consistent with an $\mathrm{ER} \alpha$ regulation of the PAK4 gene in breast cancer.

Interestingly, we found that tamoxifen induced PAK4 mRNA expression in MCF-7 cells (Figure 3F). To avoid off-target effects of tamoxifen, $1 \mu \mathrm{m}$ tamoxifen was used to treat MCF-7 cells for $12 \mathrm{~h}$. The ER $\alpha$ downstream target gene, IL-20, was used as a positive control for the tamoxifen treatment. The tamoxifen mediated increase in PAK4 expression may allow PAK4 to influence the tamoxifen response.

\section{PAK4-inhibition decreases ER $\alpha$ protein levels, ER $\alpha$ signaling and E2-mediated cell proliferation}

While ER $\alpha$ signaling regulated PAK4 expression, we also wanted to find out if PAK4 may regulate ER $\alpha$ signaling. Specifically, in the light of group II PAKinhibition leading to $\mathrm{ER} \alpha$ antagonist (tamoxifen) sensitization, we firstly analyzed the potential of PAK4inhibition on ER $\alpha$ signaling. To this end, siRNA-mediated knock-down of PAK4 as well as the GNE-2861 compound caused decreased ER $\alpha$ protein levels in both MCF-7 and T47D human breast cancer cell lines (Figure 4A and Supplementary Figure S3A). In order to further elucidate the effect of PAK4 perturbation on ER $\alpha$ transcriptional activity, we performed an estrogen response element (ERE) luciferase assay. Interestingly, PAK4 inhibition by either siRNA or the GNE-2861 compound decreased ERE luciferase activity upon E2 treatment in both MCF-7 and T47D cells (Figure 4B and Supplementary Figure S3B). In line with this, PAK4 inhibition also decreased ER $\alpha$ target gene expression, including ADORA1, Cyclin D1, EGR3, GREB1, IL-20, PDZK1, PKIB, and PS2, both with and without E2 treatment (Figure 4C). Block of PAK4 also significantly decreased EdU incorporation in MCF7 breast cancer cells both in the presence and absence of
E2 stimulation (Figure 4D and Supplementary Figure S4). These results indicate that PAK4 strongly modulates ER $\alpha$ signaling and ER $\alpha$-regulated cell proliferation.

\section{PAK4 regulates ER $\alpha$ protein stability}

As shown in Figure 4A, PAK4 inhibition in MCF7 cells caused decreased ER $\alpha$ protein levels. Further, ER $\alpha$ mRNA levels were also detected. However, siRNAmediated PAK4 knock-down did not affect ER $\alpha$ mRNA levels (Figure 5A). Further, transfection of increasing amounts of a PAK4 expression plasmid caused a gradual increase of ER $\alpha$ protein (Figure $5 \mathrm{~B}$ ). ER $\alpha$ protein stability was then analyzed by measuring $\mathrm{ER} \alpha$ protein levels at different time points after cycloheximide (CHX) treatment. Importantly, ER $\alpha$ regulates its own mRNA expression in MCF-7 cells, making it difficult to distinguish direct effects of PAK4 on ER $\alpha$ protein levels in this cell line [43]. We therefore performed assays in HEK-293 cells, in which $\mathrm{ER} \alpha$ is not expressed. PAK4 overexpression significantly increased exogenous ER $\alpha$ protein half-life in HEK293 cells (Figure 5C). In addition, cells were treated with the proteasome inhibitor MG132, which reduces degradation of ubiquitin-conjugated proteins in mammalian cells. Interestingly, PAK4 overexpression could not further enhance the ER $\alpha$ protein level when ER $\alpha$ proteasomal degradation was inhibited by MG132 (Figure 5D) suggesting that PAK4 overexpression may prevent proteasomal degradation of ER $\alpha$. Together, our data shows that PAK4 controls ER $\alpha$ signaling via regulation of its protein stability.

\section{PAK4 regulates ER $\alpha$ signaling through phosphorylation of ER $\alpha$ Serine-305}

Given that PAK4 is a kinase, we examined if PAK4 may directly phosphorylate ER $\alpha$ and thereby affect ER $\alpha$ signaling. First, we expressed and purified fragments of ER $\alpha$ (aa 1-250; aa 251-420; aa 421-595) as GSTfusion proteins (Figure 6A), and performed an in vitro kinase assay using purified recombinant PAK4 together with the ER $\alpha$ protein fragments. Interestingly, we found PAK4-mediated phosphorylation of the ER $\alpha$ fragment aa 251-420; while none of the other parts of ER $\alpha$ were phosphorylated (Figure 6B). In order to identify the specific phosphorylation site(s), the possible threonine and serine phosphorylation sites in $\mathrm{ER} \alpha$ aa 251-420 were identified according to the PhosphoSitePlus online tool (http://www.phosphosite.org, accessed on May 2014) [44], revealing four such putative Ser/Thr kinase target sites (Figure 6A). Each of these four Ser/Thr was separately mutated into Alanines and tested for the effect of the Alamutation in terms of PAK4-mediated phosphorylation. As shown in Figure 6C, while three of these mutations had no effect on PAK4-mediated phosphorylation of $\mathrm{ER} \alpha$ aa 251-420; the ER $\alpha-\mathrm{S} 305 \mathrm{~A}$ mutation abolished 

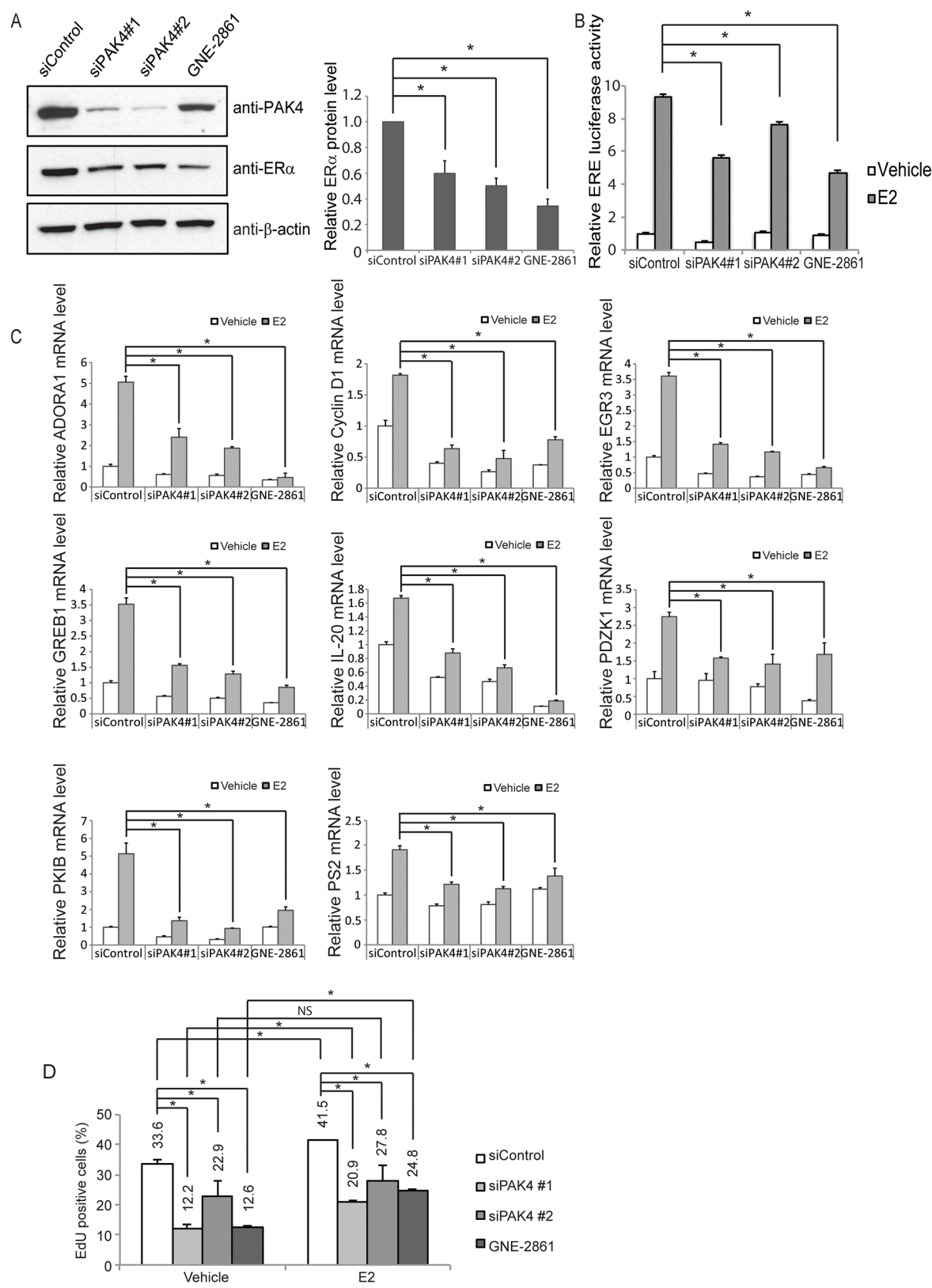

Figure 4: PAK4 inhibition impairs ERa signaling in MCF-7 cells. A. Left: PAK4 depletion or functional inhibition of group II PAKs reduces ER $\alpha$ protein levels in MCF-7 cells. MCF-7 cells were transfected with siControl or siPAK4 oligos (\#1 or \#2) for $72 \mathrm{~h}$, or treated with $50 \mu \mathrm{M}$ GNE-2861 for $24 \mathrm{~h}$. ER $\alpha$, PAK4 and $\beta$-actin levels were determined by immunoblotting. Right: Quantifications of the immunoblot. Shown values represent mean \pm s.d. $(\mathrm{n}=3) . *-P<0.05$ compared to control, according to $t$-test. B. PAK4 depletion or functional group II PAK inhibition reduces the activity of estrogen receptor-induced signal transduction in MCF-7. MCF-7 cells were transfected with siControl, siPAK4 oligos (\#1 or \#2), or treated with GNE-2861 as described above. $24 \mathrm{~h}$ before measurement, cells were transfected with an ERE luciferase reporter. After $18 \mathrm{~h}$, cells were treated with $10 \mathrm{nM}$ E2 or vehicle, and an ERE-luc luciferase assay was carried out $6 \mathrm{~h}$ after E2 addition. Shown values represent mean \pm s.d. $(\mathrm{n}=3)$, representative for three independent experiments. * $P<0.05$ compared to control, according to $t$-test. C. PAK4 depletion or pharmacological group II PAK inhibition decreases the expression of the endogenous ER $\alpha$ target genes ADORA1, Cyclin D1, EGR3, GREB1, IL-20, PDZK1, PKIB, and PS2. MCF-7 cells were transfected with siControl, siPAK4 oligos (\#1 or \#2), or treated with GNE-2861 as described above. Cells were treated with $10 \mathrm{nM}$ E2 or vehicle for $6 \mathrm{~h}$ before harvest and RNA was prepared. The mRNA expression levels of the endogenous ER $\alpha$ target genes were determined by qPCR. Shown are the results from triplicate experiments. Shown values represent mean \pm s.d. $(\mathrm{n}=3)$, representative for three independent experiments. * - $P<0.05$ compared to control, according to $t$-test. D. PAK4 depletion or functional group II PAK inhibition impairs cell proliferation in MCF-7 cells. MCF-7 cells were transfected with siControl, siPAK4 oligos (\#1 or \#2), or treated with GNE-2861 as described above. Cells were then treated with $10 \mathrm{nM}$ E2 or vehicle for $24 \mathrm{~h}$ before fixation. EdU was added at a concentration of $10 \mu \mathrm{M}$ during the last $1 \mathrm{~h}$. The cells were subject to flow cytometry analysis quantifying EdU-positive cells (Supplementary Figure S4). Shown values represent mean \pm s.d. $(\mathrm{n}=3)$, which is representative for three independent experiments. ${ }^{*}-P<0.05$, NS=not significant, as compared to control, according to $t$-test. 
PAK4-mediated ER $\alpha$-phosphorylation. Thus, Ser305 was identified as the PAK4-mediated ER $\alpha$-phosphorylation site. To test if PAK4-mediated phosphorylation of ER $\alpha$ Ser305 had any effect on ER $\alpha$ signaling within cells, we examined the ER $\alpha$ response in an ERE luciferase assay in the presence or absence of E2. Importantly, while PAK4 increased the estrogen response by wild type Flag-ER $\alpha$, the Flag-ER $\alpha-S 305 \mathrm{~A}$ mutant failed to respond to PAK4 even in the presence of E2 (Figure 6D). This suggests that PAK4 regulates ER $\alpha$ signaling through the direct phosphorylation of ER $\alpha$-Ser305. To test the influence of this phosphorylation site for protein stability, wild-type
A

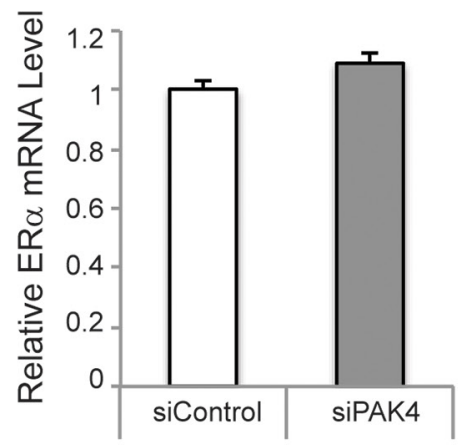

B

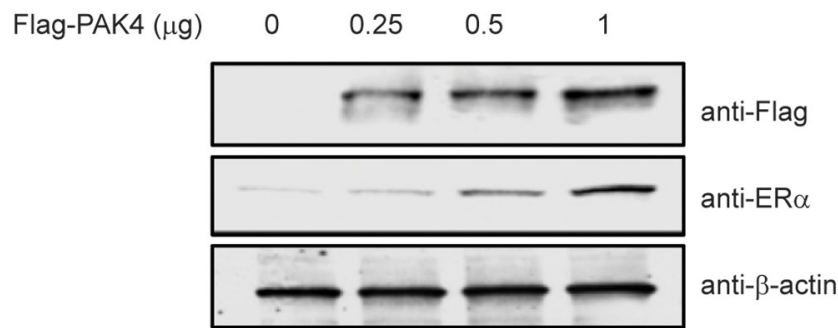

C
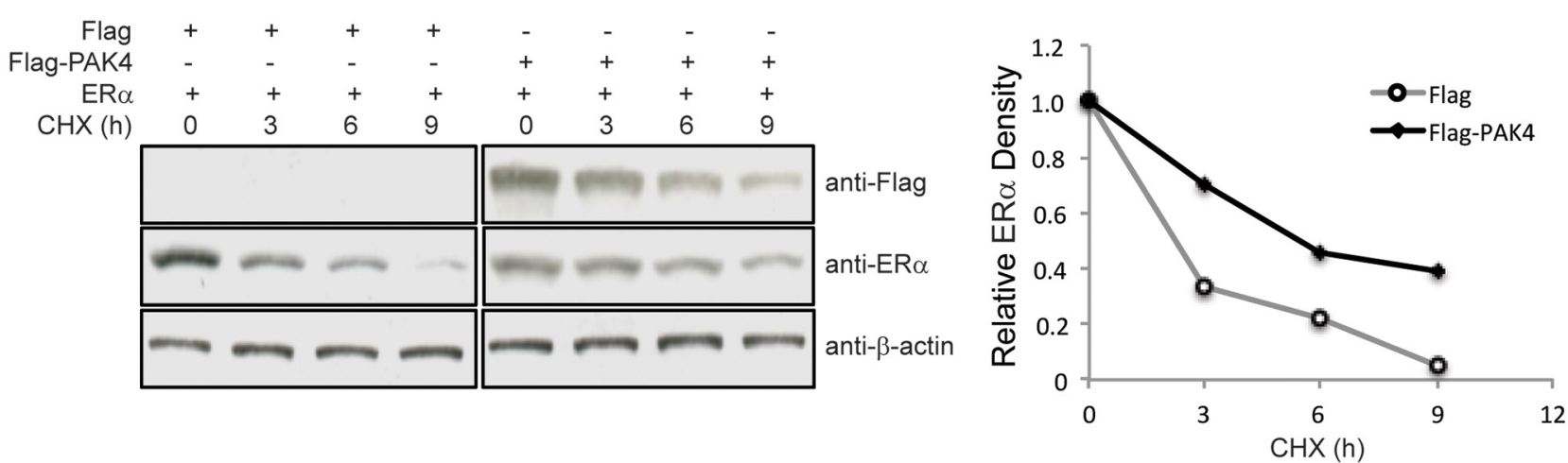

$\mathrm{D}$

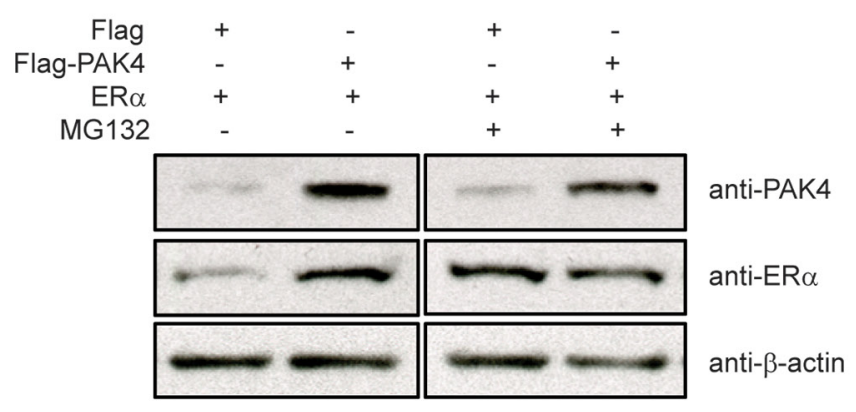

Figure 5: PAK4 regulates ER $\alpha$ protein stability. A. Depletion of PAK4 does not affect ER $\alpha$ mRNA levels. MCF-7 cells were transfected with control siRNA or PAK4 siRNA (\#1 and \#2 pool). After $72 \mathrm{~h}$, cells were harvested for analysis. ER $\alpha$ mRNA was measured by qPCR. Shown values represent mean \pm s.d. $(n=3)$. B. Over-expression of PAK4 increases ER $\alpha$ protein levels. MCF-7 cells were transfected with varying amounts of a Flag-PAK4 plasmid, and Flag-PAK4, ER $\alpha$ and $\beta$-actin levels were determined by immunoblotting. C. Over-expression of PAK4 increases ER $\alpha$ protein stability. HEK293 cells were transfected with ER $\alpha$ together with Flag-PAK4 or a Flag control plasmid. Cells were treated with $100 \mu \mathrm{M}$ cycloheximide (CHX) for the indicated times. Flag-PAK4, ER $\alpha$ and $\beta$-actin levels were determined by immunoblotting. The relative ER $\alpha$ protein levels were quantified by ImageJ and normalized to the zero time point ER $\alpha$ levels (before CHX treatment). Two-sample Kolmogorov-Smirnov test (two-sample KS-test) of the curve distributions in three distinct experiments yielded a statistically discernable difference between Flag control and Flag-PAK4 $(P=0.03)$. D. The proteasome inhibitor MG132 increases ER $\alpha$ protein level in a similar manner as PAK4 overexpression. HEK293 cells were transfected with ER $\alpha$ together with

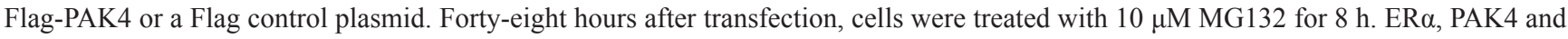
$\beta$-actin levels were determined by immunoblot analysis. The results are representative for three independent experiments. 


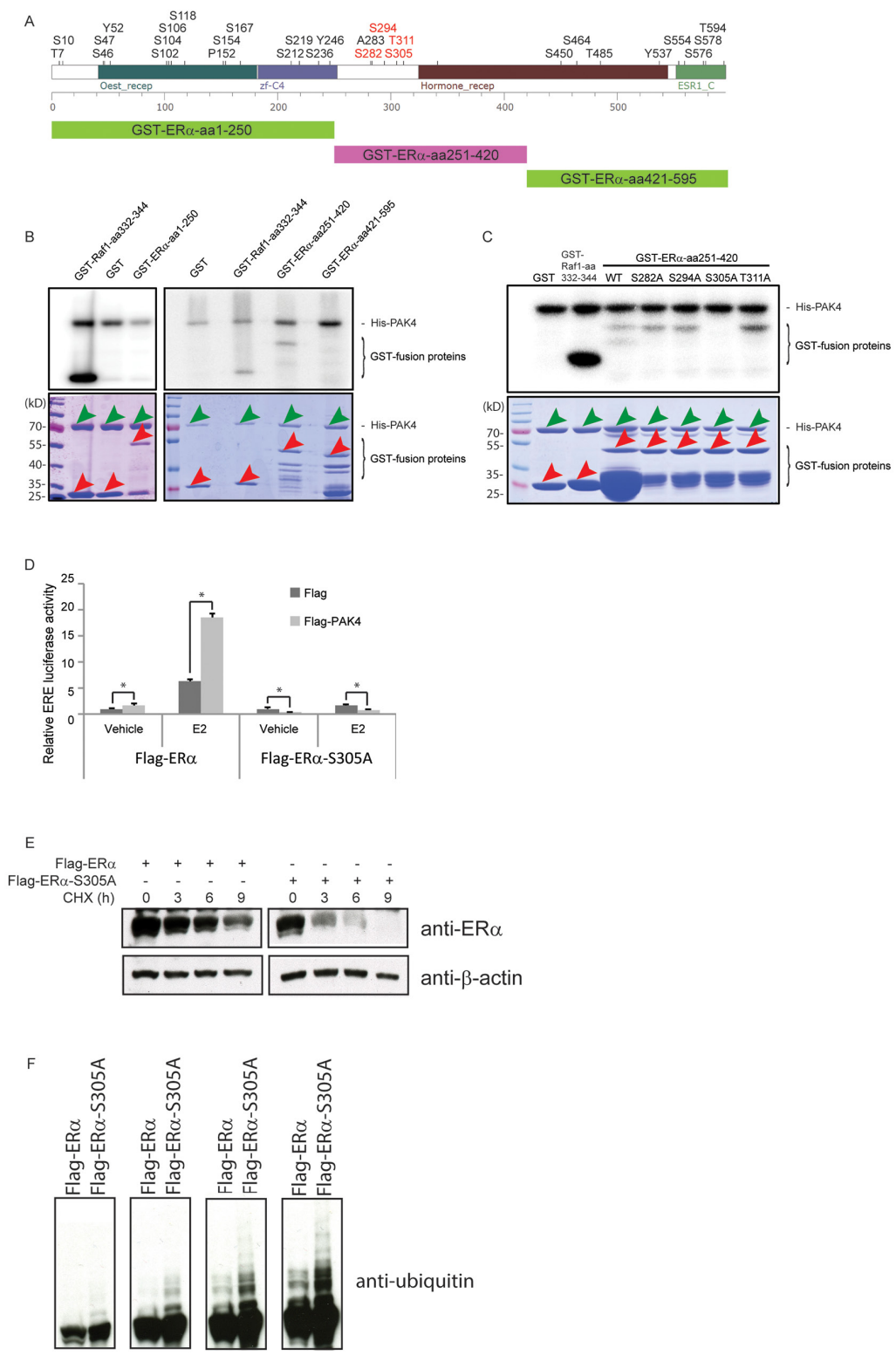

Figure 6: PAK4 regulation of ERo signaling through phosphorylation of ERo-Ser305. A. Upper panel: prediction of phosphorylation modification sites of ER $\alpha$ using the PhosphoSitePlus online tool (http://www.phosphosite.org, accessed on May 2014). The four putative Ser/Thr kinase target sites in ER $\alpha$ aa 251-420 are in red. Lower panel: the three different fragments for which we produced GST-fusion proteins used in B. B. PAK4 phosphorylates the ER $\alpha$ fragment aa 251-420. His-PAK4 phosphorylation of $E R \alpha$ was analyzed by in vitro phosphorylation using recombinant His-PAK4 together with GST-ER $\alpha$ fragments as substrates, using GST alone as a negative control and GST-Rafl-aa332-344 as a positive control (upper panel). The lower panel shows the amounts of His-PAK4 proteins (green arrows) and GST-fusion proteins (red arrows) used in the assay by Coomassie Brilliant Blue gel staining. Bands not demarcated by arrows likely represent degradation products. A size marker is displayed in the left lane of each gel. C. PAK4 phosphorylates ER $\alpha$ at Serine 305. Recombinant His-PAK4 was used as the kinase (green arrows in lower panel), and purified GST-ER $\alpha$ aa 251-420 protein fragments with or without mutations (red arrows in lower panel) were substrates. A GST-Rafl-aa332-344 fusion protein was used as a positive control and GST only was used as a negative control (Also red arrows in lower panel). The upper panel is an autoradiography image, the lower panel is a Coomassie Brilliant Blue staining. D. ER $\alpha$-Ser305 phosphorylation is necessary for the PAK4 mediated ER $\alpha$ signaling. Flag control or Flag-PAK4 and wild type Flag-ER $\alpha$ or Flag-ER $\alpha$-S305A were transfected in the indicated combinations in HEK293 cells. $24 \mathrm{~h}$ before measurement, cells were transfected with an ERE luciferase reporter. After $18 \mathrm{~h}$, cells were treated with $10 \mathrm{nM}$ E2 or vehicle, and an ERE-luc luciferase assay was carried out $6 \mathrm{~h}$ after E2 addition. Shown values represent mean $\pm \mathrm{s}$ s.d. $(\mathrm{n}=3$ ), which is representative for three independent experiments. * $P<0.05$ for Flag-PAK4 group versus control, according to $t$-test. E. ER $\alpha$-S305A is less stable than wild-type ER $\alpha$. HEK293 cells were transfected with wild-type Flag-ER $\alpha$ or Flag-ER $\alpha$-S305A plasmids. Forty-eight hours after transfection, cells were treated with $100 \mu \mathrm{M}$ cycloheximide (CHX) for the indicated times. ER $\alpha$ and $\beta$-actin levels were determined by immunoblotting. The results are representative for three independent experiments. F. ER $\alpha$-S305A displays stronger ubiquitination than wild-type ER $\alpha$. HEK293 cells were transfected with wild-type Flag-ER $\alpha$ or Flag-ER $\alpha$-S305A plasmid. Forty-eight hours after transfection, cells were treated with $10 \mu \mathrm{M}$ MG132 for $8 \mathrm{~h}$. Ubiquitin were detected by immunoblotting. The panel displays varying exposure times increasing from the left to the right. 
Flag-ER $\alpha$ and Flag-ER $\alpha-S 305 \mathrm{~A}$ were overexpressed in HEK293 cells and the stability was determined after $\mathrm{CHX}$ treatment. Interestingly, Flag-ER $\alpha-\mathrm{S} 305 \mathrm{~A}$ displayed a lower stability than wild-type Flag-ER $\alpha$ (Figure 6E). As shown in Figure 6F, Flag-ER $\alpha$-S305A was also more strongly ubiquitinated than wild-type Flag-ER $\alpha$, which is consistent with a more repid proteasome-mediated degradation of the Flag-ER $\alpha$-S305A mutant.

\section{DISCUSSION}

Tamoxifen resistance is a significant clinical problem in breast cancer, causing tumor relapse and progression [45]. However, the mechanism for tamoxifen resistance is not entirely clear, although multiple pathways have been implicated in the presumably diverse mechanisms responsible for tamoxifen resistance, such as estrogen signaling pathways, cell cycle signaling pathways and growth factor receptor pathways [46]. Either loss of ER $\alpha$ function or increased function (or loss of control) can be associated with tamoxifen resistance. The phosphorylation of ER $\alpha$ Ser305 results in activation of $E R \alpha$, which could render estrogen-hypersensitivity and antiestrogen-insensitivity [13, 47]. In fact, experimental and clinical data suggest that $\mathrm{ER} \alpha \operatorname{Ser} 305$ phosphorylation may promote tamoxifen resistance in breast cancer [12-14, 47-49]. One possible mechanism for the ER $\alpha$ Ser305 phosphorylation in tamoxifen resistance is an altered orientation between ER $\alpha$ and its coactivator SRC-1, which elevates the ER $\alpha$ transcription activity in the presence of tamoxifen [47, 48]. Moreover, phosphorylation of ER $\alpha$ Ser305 by PAK1 can trigger a secondary phosphorylation on Ser118, which may also contribute to tamoxifen resistance [13]. Our finding that the group II PAK inhibitor GNE-2861, which does not inhibit group I PAKs (PAK1, 2, 3) [31], restored tamoxifen sensitivity, in combination with the induction of tamoxifen resistance by PAK4 overexpression and the correlation of high PAK4 expression with poor patient outcome after tamoxifen treatment now suggest that PAK4 may promote tamoxifen resistance in ER $\alpha$ positive breast cancer. Our identification of PAK4-mediated phosphorylation of ER $\alpha$-Ser305 is particularly interesting in the light of the previous correlation between ER $\alpha$ Ser305-phosphorylation and tamoxifen-resistance in breast cancer patients [49]. However, given that ER $\alpha$ Ser305 phosphorylation can be mediated by at least also PAK1, a group I PAK member $[49,50]$, and by PKA $[47,48,51]$, the relative importance of these kinases in breast cancer remains unclear, considering also that both PAK1 and PAK4 have been found overexpressed in human breast cancer $[10,21]$. However, while high PAK4 expression displayed consistent correlation with poor outcome of endocrine treated breast cancer patients in two distinct large databases, no other PAK member displayed such a consistent correlation with the patient outcome. However, while the correlation of high PAK4 expression and poor patient outcome is consistent with a functional role in tamoxifen resistance, it should be noted that the PAK kinases are regulated also at the level of kinase activity. Unfortunately, there is at present no good marker for PAK activity that can be traced in patient materials and therefore, it remains unclear if the activity of any of the PAKs may be correlated with disease outcome. Also, in relation to the PAK4 expression level correlation with patient outcome, it should be noted that PAK4 in breast cancer may play other or additional roles to tamoxifen resistance that may influence that patient outcome. Nevertheless, our experimental data indicate that PAK4 may be a suitable pharmacological target for the development of therapy to sensitize breast cancer to tamoxifen treatment.

In addition, we here showed that ER $\alpha$ binds to the PAK4 gene and promotes PAK4 transcription upon E2 treatment, while the increased PAK4 in turn phosphorylates and stabilizes the ER $\alpha$ protein, thereby enhancing ER $\alpha$ signaling and transcription of ER $\alpha$ target genes, including PAK4. This positive feed-forward loop may also promote breast cancer cell proliferation and tamoxifen resistance. So far, PAK4 is the only PAK family member found to be a transcriptional target of $\mathrm{ER} \alpha$. Together, our data indicate that PAK4 may have an unusually tight relationship with ER $\alpha$ signaling.

A related mechanism for tamoxifen resistance is through the loss of expression of Rho guanine dissociation inhibitor $\alpha$ (RhoGDI $\alpha$ ), a negative regulator of the Rho family proteins Rho, Rac-1 and Cdc42 [11]. Consequently, loss of RhoGDI $\alpha$ caused increased Rho, Rac-1 and Cdc42 activities in breast cancer cells [11]. Given that PAK1 can act downstream of Rac-1 and Cdc42, Barone et al. proposed that PAK1-mediated phosphorylation of ER $\alpha$-Ser305 was coupled to the RhoGDI $\alpha$-regulation of tamoxifen resistance [11]. However, the possible functional involvement of Rho, Rac-1, Cdc42, or PAK1 in the RhoGDI $\alpha$ control of tamoxifen resistance has not been experimentally addressed. In this context, it may be noted that all the six PAK family members are downstream effectors of Rac-1 and Cdc42 [52, 53]. This means that our finding of a role for PAK4 in tamoxifen resistance and in regulating ER $\alpha$ signaling through the phosphorylation of Ser-305 may suggest that PAK4 activation could potentially act down-stream of loss of RhoGDI $\alpha$ in induction of tamoxifen resistance.

Recently, there has been an increasing interest in using PAK family kinases as targets in cancer $[8,16]$. To this end, the group I p21-activated kinase inhibitor FRAX1036, in combination with taxane, induced apoptosis in luminal breast cancer cells [32]. Here we showed that GNE-2861, a small molecule selectively inhibiting group II PAKs, but with no effect on group I PAKs [31], overcomes tamoxifen resistance. Given that PAK4 overexpression promoted tamoxifen resistance, 
and that PAK4 displayed the only consistent correlation in both databases among group II PAKs to breast cancer patient outcome, and that depletion of PAK4 by siRNA gave very similar effects on ER $\alpha$ signaling as GNE2861, this suggests that GNE-2861 may act to restore tamoxifen sensitivity by the inhibition of PAK4, although we cannot exclude possible effects onto other targets.

\section{MATERIALS AND METHODS}

\section{Mammalian cell expression constructs}

The ER $\alpha$ plasmid and Flag-ER $\alpha$ plasmid was described previously [54]. A Flag-ER $\alpha-S 305$ A mutant was generated using the Flag-ER $\alpha$ and the QuickChange Site-Directed Mutagenesis kit (200518-5, Agilent Technologies, Santa Clara, USA). The Flag-PAK4 plasmid was described in previous studies [22, 24].

\section{Cell culture and transient transfections}

DMEM (41965-039, Life Technologies, Grand Island, USA) with $10 \%$ fetal bovine serum (FBS) was used to culture MCF-7 (purchased from ATCC), MCF-7/ Control (kindly provided by Dr. Janne Lehtiö), MCF-7/ LCC2 (kindly provided by Dr. Janne Lehtiö), HEK293 (purchased from ATCC) and COS-7 cells (purchased from ATCC). RPMI-1640 (42401-018, Life Technologies, Grand Island, USA) supplemented with $10 \%$ FBS, was used to culture T47D (purchased from ATCC) cells. Phenol red-free DMEM (11880-028, Life Technologies, Grand Island, USA), supplemented with 5\% DCC-FCS serum (12676029, Life Technologies, Grand Island, USA) was utilized for all the experiments involving $17 \beta$-estradiol (E2) treatment. MCF-7 cells with Flag-BAP (bacterial alkaline phosphatase) or Flag-PAK4 stable expression were cultured in DMEM medium supplemented with 10\% FBS and $150 \mu \mathrm{g} / \mathrm{ml} \mathrm{G} 418$ (Invitrogen) [25]. All cells were cultured in a humidified incubator at $37^{\circ} \mathrm{C}$ with $5 \%$ $\mathrm{CO}_{2}$. Transient transfections of plasmids were performed according to the manufacturer's protocol: $8 \mu \mathrm{g}$ of total DNA was transfected for each 100-mm cell culture dish (90\% cell confluence) using Lipofectamine 2000 (11668027, Invitrogen, Carlsbad,CA, USA).

\section{siRNA transfection, PAK4 inhibitor treatment, E2 treatment and tamoxifen treatment}

$50 \%$ confluent cells were transfected with $30 \mathrm{nM}$ small interfering RNA (siRNA) using Lipofectamine RNAiMAX Reagent (13778-150, Invitrogen, Carlsbad, USA) according to the Manufacturer's protocol. The control siRNA (targeting sequences: 5'-TTCTCCGAACGTGTCACG-3') and the two human PAK4 siRNA (targeting sequences: \#1:
5'-AGCTGGTGGCCGTCAAGAA-3'; \#2: 5'-CGAGGTG GTAATCATGA-3') were purchased from GenePharma, Shanghai, China. The cells were harvested at day 3 after transfection. The GNE-2861 compound (Compound 17) was kindly provided by Genentech Inc (South San Francisco, CA, USA) [31]. GNE-2861 was added to the culture medium $24 \mathrm{~h}$ before harvest. For the E2 combination treatment, cells were transfected with siRNA for $2 \mathrm{~d}$, and then treated with $10 \mathrm{nM} \mathrm{E} 2$ or vehicle for another 24 h. Alternatively, cells were treated with GNE-2861 together with $10 \mathrm{nM}$ E2 or vehicle for $24 \mathrm{~h}$.

\section{Immunoblotting}

Cells were lysed with NP-40 cell lysis buffer (50 $\mathrm{mM}$ Tris- $\mathrm{HCl} \mathrm{pH} 7.5,150 \mathrm{mM} \mathrm{NaCl}, 5 \mathrm{mM} \mathrm{MgCl}, 1 \mathrm{mM}$ EDTA, 10\% Glycerol, 1\% NP-40), with freshly added Protease inhibitor (11697498001, Roche, Mannheim, Germany) according to the manufacturer's protocol. $20 \mu \mathrm{g}$ of cell lysate was loaded into each well for SDSpolyacrylamide gel electrophoresis (PAGE) and was electroblotted onto nitrocellulose membranes (10600008, GE healthcare, Freiburg, Germany). Membranes were incubated with antibodies against $\beta$-Actin (A5316) from Sigma (Saint Louis, USA); c-myc (SC40) from Santa Cruz (Dallas, USA); ER $\alpha$ (SC543) from Santa Cruz (Dallas, USA); Flag (F3165) from Sigma (Saint Louis, USA); GFP (MAB2510) from Millipore (Temecula, USA); ubiquitin (FL76) from Santa Cruz (Dallas, USA); PAK4 (total) pAb (6508) generated in our laboratory [25].

\section{RNA extraction, reverse transcription-PCR (RT-PCR) and quantitative real-time PCR (qPCR) analysis}

RNeasy kits were utilized for RNA extraction (74104, Qiagen, Hilden, Germany). RT-PCR was performed using standard procedures, using TaqMan Reverse Transcription Reagents (N808-0234, Applied Biosystems, Foster City, USA). qPCR experimental procedures were previously described [55]. qPCR was performed in a 7500 Fast Real-Time PCR System (Applied Biosystems, Foster City, CA) with FastStart Universal SYBR Green Master mix (04913914001, Roche, Indianapolis, USA) according to conditions specified by the manufacturer. The $36 \mathrm{~B} 4$ gene was used as an internal control for normalization. Primer sequences for qPCR are shown in more detail (Supplementary Table S1). The specificity of all primer pairs was checked by melting curve analysis.

\section{Chromatin immunoprecipitation (ChIP) assays and ChIP-Sequencing (ChIP-Seq)}

MCF-7 cells were seeded in $150 \mathrm{~mm}$-dishes and grown in phenol red-free DMEM (11880-028, Life 
Technologies, Grand Island, USA), supplemented with 5\% DCC-FCS serum (12676029, Life Technologies, Grand Island, USA). Cells were treated with vehicle or $10 \mathrm{nM}$ E2 for $45 \mathrm{~min}$ and chromatin immunoprecipitation (ChIP) was performed as previously described [56], using anti-ER $\alpha$ antibody HC-20 (Santa Cruz, CA) or normal rabbit IgG (Santa Cruz, CA). The immunoprecipitated DNA was assessed by qPCR. Primer sequences used for qPCR are given in more detail (Supplementary Table S1). ChIP-Seq was performed using the Illumina Genome Analyzer following the Manufacturer's protocols. The raw sequencing image data were analyzed by the Illumina analysis pipeline, mapped to the human reference genome (hg19, GRCh37) using Bowtie. Significantly enriched ER $\alpha$ binding regions, comparing to IgG control were identified using the Partek Genomics Suite (Partek ${ }^{\circledR}$ software. Copyright, Partek Inc., St Louis, $\mathrm{MO})$.

\section{Flow cytometry}

EdU (5-ethynyl-2'-deoxyuridine) labeled DNA staining was performed according to the Manufacturer's protocol (C10424, Life Technologies, Eugene, USA) as described in a previous study [57]. $10 \mu \mathrm{M}$ EdU was added for $1 \mathrm{~h}$ before fixation by ice-cold Ethanol (final concentration 70\%). The BD LSR II flow cytometer (BD Bioscience) was used to measure the DNA incorporation signal and fluorescence was measured in the FL-4 channel.

\section{ERE luciferase assays}

Cells were co-transfected with ERE/Luci (firefly luciferase) and phRL/CMV (Renilla luciferase) plasmids. Luciferase activity was measured using the DualLuciferase Reporter Assay System (E1910, Promega, Mannheim, Germany).

\section{WST-1 cell proliferation assay}

$10^{4}$ cells were seeded into each well of 96-well plates. $1 \mathrm{~h}$ before reading the plate, WST-1 reagent (11644807001, Roche, Indianapolis, USA) (1:10 diluted by cell culture medium) was added to each well. The absorbance of the samples was measured against a blank background control using a microplate reader at $450 \mathrm{~nm}$.

\section{Protein stability assay}

Cells were treated with $100 \mu \mathrm{M}$ cycloheximide (CHX) (C4859, Sigma) for different times or $10 \mu \mathrm{M}$ MG132 (SC-201270, Santa Cruz) for 8 h. ER $\alpha$ protein levels were analyzed by immunoblotting. Quantification of immunoblotted bands (X-ray film blackening) was performed by ImageJ.

\section{In vitro kinase activity assay}

$\mathrm{ER} \alpha$ fragments corresponding to amino acid (aa) 1-250; aa 251-420; aa 421-595 and the mutants ER $\alpha$ aa 251-420-S282A; aa 251-420-S294A; aa 251-420-S305A and aa 251-420-T311A were individually expressed as GST-fusion proteins using the bacterial expression vector pGEX-4t-1 (27-1542-01, GE Healthcare, Uppsala, Sweden). GST-fusion proteins were purified using glutathione-Sepharose beads (17-0756-01, GE Healthcare, Uppsala, Sweden) according to the Manufacturer's protocol. His-PAK4 fusion protein was produced as described [26]. In vitro protein phosphorylation assays were performed as described [26]. Briefly, ER $\alpha$ phosphorylation was determined in a kinase reaction buffer (50 mM Hepes, pH 7.5, 10 mM MgCl2, 2 mM MnCl2, 0.2 $\mathrm{mM}$ dithiothreitol) in the presence of $30 \mu \mathrm{M}$ ATP and 10 $\mu \mathrm{Ci}$ of $\left[\gamma_{-}{ }^{32} \mathrm{P}\right]$ ATP and in the presence of the kinase $(5 \mu \mathrm{g}$ of His-PAK4) and $5 \mu \mathrm{g}$ of the substrate (GST, GST-Raf1aa332-344, or GST-ER $\alpha$ fragments) for $30 \mathrm{~min}$ at $30^{\circ} \mathrm{C}$. The reaction was stopped by adding sample loading buffer and heating at $95^{\circ} \mathrm{C}$ for $5 \mathrm{~min}$. Samples were separated by $10 \%$ SDS-PAGE and visualized by autoradiography with the PhosphorImager system (Molecular Imager FX, Bio$\mathrm{Rad})$.

\section{Ubiquitination assays}

HEK-293 cells were transfected with wild-type Flag-ER $\alpha$ or Flag-ER $\alpha-S 305$ A. Forty-eight hours after transfection, cells were treated with $10 \mu \mathrm{M}$ MG132 for 8 h. Ubiquitin was detected by immunoblotting.

\section{Public datasets}

Two publicly available databases were used to explore the prognostic role of PAK4 gene expression in ER $\alpha$ positive clinical samples. The KMplot online tool (http://www.kmplot.com, accessed on April 2015) assembled gene expression data from Affymetrix platforms of different breast cancer cohorts and allows Kaplan-Meier analysis of selected genes [34]. On the KMplot platform, ER $\alpha$ positive patients having received only endocrine therapy $(n=725)$ or more specifically, only tamoxifen $(n=650)$ as adjuvant treatment were selected. All annotated Affymetrix probesets with a quality estimated as Jetset best probesets for each of the gene in the A arrays were analyzed [58]. For each member of the PAK family, we used the latest version of the hgu133a. $\mathrm{db}$ Bioconductor package (version 3.1.3) as annotation. In case of multiple probesets per gene, the optimal probeset according to the Jetset method was selected for further analysis [58] (Supplementary Table S2). The selected probesets for PAKs are as following: PAK1 209615_s_at; PAK2 208877_at; PAK3 214607 at; PAK4 203154_s_at; PAK5 210721_s_at; PAK6 219461_at. The Metabric 
gene expression normalized data were downloaded from the European genome-phenome archive platform (http:// www.ebi.ac.uk/ega/studies/EGAS00000000083, accessed on March 2015). Metabric used the Illumina HT-12 v3 platform for transcriptional profiling of 1992 breast cancer tumor patients [33]. Clinical variables were obtained from the supplementary material of the original publication [33]. No information was given in the Metabric cohort concerning the type of administered endocrine therapy. $915 \mathrm{ER} \alpha$ positive endocrine therapy treated patients were available in this cohort. The probe for each PAK gene that displays the highest interquartile range was used for the patient outcome analysis (Supplementary Table S3). For two of the PAK genes, more than one probe was available. The ILMN_1712687 probe was selected for PAK2 and the ILMN_1728887 probe was selected for PAK4, since they display the highest interquartile range.

\section{Statistics}

The prognostic role of PAK4 in ER $\alpha$ positive endocrine therapy and tamoxifen treated patients was explored for the Relapse Free Survival (KMplot) and Disease Specific Survival (Metabric) endpoints. Deaths of an unknown cause were excluded from analyses of the Disease Specific Survival endpoint. PAK4 gene expression was dichotomized according to an auto-selected best cutoff (KMplot) or by median-based cut-off (Metabric). The univariable prognostic role of PAK4 (above vs. below the cut-off) was visualized using Kaplan-Meier estimates and compared using log-rank test. All analyses of the Metabric cohort were stratified by site, which is suggested in the original publication [33]. Similar methods were used for all other PAK family genes. The analysis was exploratory and therefore, no multiple testing correction was applied. Spearman correlation analysis was used to calculate the correlation between the expression of the PAK4 and ESR1 genes in the Metabric dataset. Statistical analyses of disease outcome were performed using the KMplot platform and the R statistical software v3.1.0. Two-sample Kolmogorov-Smirnov test (two-sample KS-test) was used for immunoblot quantifications of the $\mathrm{CHX}$ experiment. Cox regression analysis and $t$-test were utilized for other statistical analyses. $P<0.05$ was considered to represent statistical discernibility of differences.

\section{ACKNOWLEDGMENTS}

This study makes use of data (Metabric) generated by the Molecular Taxonomy of Breast Cancer International Consortium (Funding for the project was provided by Cancer Research UK and the British Columbia Cancer Agency Branch.). We thank Genentech for kindly providing the GNE-2861 compound, Dr. Janne Lehtiö for sharing MCF-7/Control and MCF-7/LCC2 cell lines, and Dr. Chen Suo for statistical support.

\section{CONFLICTS OF INTEREST}

The authors declare that they have no competing interests.

\section{GRANT SUPPORT}

Ting Zhuang and Jian Zhu were supported by scholarships from the China Scholarship Council (CSC). This study was supported by the Swedish Cancer Society, the Swedish Research Council, the Breast Cancer Theme Center (BRECT), the Center for innovative medicine at Karolinska Institutet and the Robert Lundberg Memorial Foundation.

\section{REFERENCES}

1. DeSantis C, Ma J, Bryan L and Jemal A. Breast cancer statistics, 2013. CA: a cancer journal for clinicians. 2014; 64:52-62.

2. Jakesz R, Smith CA, Aitken S, Huff K, Schuette W, Shackney $\mathrm{S}$ and Lippman M. Influence of cell proliferation and cell cycle phase on expression of estrogen receptor in MCF-7 breast cancer cells. Cancer research. 1984; 44:619-625.

3. Lin CY, Strom A, Vega VB, Kong SL, Yeo AL, Thomsen JS, Chan WC, Doray B, Bangarusamy DK, Ramasamy A, Vergara LA, Tang S, Chong A, Bajic VB, Miller LD, Gustafsson JA, et al. Discovery of estrogen receptor alpha target genes and response elements in breast tumor cells. Genome biology. 2004; 5:R66.

4. Clarke R, Leonessa F, Welch JN and Skaar TC. Cellular and molecular pharmacology of antiestrogen action and resistance. Pharmacological reviews. 2001; 53:25-71.

5. Haagenson KK, Zhang JW, Xu Z, Shekhar MP and Wu GS. Functional analysis of MKP-1 and MKP-2 in breast cancer tamoxifen sensitivity. Oncotarget. 2014; 5:1101-1110.

6. de Leeuw R, Neefjes J and Michalides R. A role for estrogen receptor phosphorylation in the resistance to tamoxifen. International journal of breast cancer. 2011; 2011:232435.

7. Knaus UG and Bokoch GM. The p21Rac/Cdc42-activated kinases (PAKs). The international journal of biochemistry \& cell biology. 1998; 30:857-862.

8. Radu M, Semenova G, Kosoff R and Chernoff J. PAK signalling during the development and progression of cancer. Nature reviews Cancer. 2014; 14:13-25.

9. Bostner J, Ahnstrom Waltersson M, Fornander T, Skoog L, Nordenskjold B and Stal O. Amplification of CCND1 and PAK1 as predictors of recurrence and tamoxifen resistance in postmenopausal breast cancer. Oncogene. 2007; 26:6997-7005.

10. Holm C, Rayala S, Jirstrom K, Stal O, Kumar R and Landberg G. Association between Pak1 expression and subcellular localization and tamoxifen resistance in breast cancer patients. Journal of the National Cancer Institute. 2006; 98:671-680. 
11. Barone I, Brusco L, Gu G, Selever J, Beyer A, Covington KR, Tsimelzon A, Wang T, Hilsenbeck SG, Chamness GC, Ando S and Fuqua SA. Loss of Rho GDIalpha and resistance to tamoxifen via effects on estrogen receptor alpha. Journal of the National Cancer Institute. 2011; 103:538-552.

12. Bostner J, Skoog L, Fornander T, Nordenskjold B and Stal O. Estrogen receptor-alpha phosphorylation at serine 305, nuclear p21-activated kinase 1 expression, and response to tamoxifen in postmenopausal breast cancer. Clinical cancer research : an official journal of the American Association for Cancer Research. 2010; 16:1624-1633.

13. Rayala SK, Talukder AH, Balasenthil S, Tharakan R, Barnes CJ, Wang RA, Aldaz CM, Khan S and Kumar R. $\mathrm{P} 21$-activated kinase 1 regulation of estrogen receptor-alpha activation involves serine 305 activation linked with serine 118 phosphorylation. Cancer research. 2006; 66:1694-1701.

14. Kok M, Zwart W, Holm C, Fles R, Hauptmann M, Van't Veer LJ, Wessels LF, Neefjes J, Stal O, Linn SC, Landberg $\mathrm{G}$ and Michalides R. PKA-induced phosphorylation of ERalpha at serine 305 and high PAK1 levels is associated with sensitivity to tamoxifen in ER-positive breast cancer. Breast cancer research and treatment. 2011; 125:1-12.

15. Lee SR, Ramos SM, Ko A, Masiello D, Swanson KD, Lu ML and Balk SP. AR and ER interaction with a p21-activated kinase (PAK6). Molecular endocrinology. 2002; 16:85-99.

16. Dart AE and Wells CM. P21-activated kinase 4--not just one of the PAK. European journal of cell biology. 2013; 92(4-5):129-138.

17. Callow MG, Clairvoyant F, Zhu S, Schryver B, Whyte DB, Bischoff JR, Jallal B and Smeal T. Requirement for PAK4 in the anchorage-independent growth of human cancer cell lines. The Journal of biological chemistry. 2002; 277:550-558.

18. Chen S, Auletta T, Dovirak O, Hutter C, Kuntz K, El-ftesi S, Kendall J, Han H, Von Hoff DD, Ashfaq R, Maitra A, Iacobuzio-Donahue CA, Hruban RH and Lucito R. Copy number alterations in pancreatic cancer identify recurrent PAK4 amplification. Cancer biology \& therapy. 2008; 7:1793-1802.

19. Siu MK, Chan HY, Kong DS, Wong ES, Wong OG, Ngan HY, Tam KF, Zhang H, Li Z, Chan QK, Tsao SW, Stromblad $\mathrm{S}$ and Cheung AN. p21-activated kinase 4 regulates ovarian cancer cell proliferation, migration, and invasion and contributes to poor prognosis in patients. Proceedings of the National Academy of Sciences of the United States of America. 2010; 107:18622-18627.

20. Kimmelman AC, Hezel AF, Aguirre AJ, Zheng H, Paik JH, Ying H, Chu GC, Zhang JX, Sahin E, Yeo G, Ponugoti A, Nabioullin R, Deroo S, Yang S, Wang X, McGrath JP, et al. Genomic alterations link Rho family of GTPases to the highly invasive phenotype of pancreas cancer. Proceedings of the National Academy of Sciences of the United States of America. 2008; 105:19372-19377.
21. Liu Y, Xiao H, Tian Y, Nekrasova T, Hao X, Lee HJ, Suh N, Yang CS and Minden A. The pak4 protein kinase plays a key role in cell survival and tumorigenesis in athymic mice. Molecular cancer research : MCR. 2008; 6:1215-1224.

22. Qu J, Cammarano MS, Shi Q, Ha KC, de Lanerolle P and Minden A. Activated PAK4 regulates cell adhesion and anchorage-independent growth. Molecular and cellular biology. 2001; 21:3523-3533.

23. Wells CM, Abo A and Ridley AJ. PAK4 is activated via PI3K in HGF-stimulated epithelial cells. Journal of cell science. 2002; 115(Pt 20):3947-3956.

24. Zhang H, Li Z, Viklund EK and Stromblad S. P21-activated kinase 4 interacts with integrin alpha $\mathrm{v}$ beta 5 and regulates alpha $\mathrm{v}$ beta 5 -mediated cell migration. The Journal of cell biology. 2002; 158:1287-1297.

25. Li Z, Lock JG, Olofsson H, Kowalewski JM, Teller S, Liu Y, Zhang $\mathrm{H}$ and Stromblad S. Integrin-mediated cell attachment induces a PAK4-dependent feedback loop regulating cell adhesion through modified integrin alpha v beta 5 clustering and turnover. Molecular biology of the cell. 2010; 21:3317-3329.

26. Li Z, Zhang H, Lundin L, Thullberg M, Liu Y, Wang Y, Claesson-Welsh L and Stromblad S. p21-activated kinase 4 phosphorylation of integrin beta5 Ser-759 and Ser-762 regulates cell migration. The Journal of biological chemistry. 2010; 285:23699-23710.

27. Ahmed T, Shea K, Masters JR, Jones GE and Wells CM. A PAK4-LIMK1 pathway drives prostate cancer cell migration downstream of HGF. Cellular signalling. 2008; 20:1320-1328.

28. Dan C, Kelly A, Bernard O and Minden A. Cytoskeletal changes regulated by the PAK4 serine/threonine kinase are mediated by LIM kinase 1 and cofilin. The Journal of biological chemistry. 2001; 276:32115-32121.

29. Gnesutta N, Qu J and Minden A. The serine/threonine kinase PAK4 prevents caspase activation and protects cells from apoptosis. The Journal of biological chemistry. 2001; 276:14414-14419.

30. Murray BW, Guo C, Piraino J, Westwick JK, Zhang C, Lamerdin J, Dagostino E, Knighton D, Loi CM, Zager M, Kraynov E, Popoff I, Christensen JG, Martinez R, Kephart $\mathrm{SE}$, Marakovits J, et al. Small-molecule p21-activated kinase inhibitor PF-3758309 is a potent inhibitor of oncogenic signaling and tumor growth. Proceedings of the National Academy of Sciences of the United States of America. 2010; 107:9446-9451.

31. Staben ST, Feng JA, Lyle K, Belvin M, Boggs J, Burch JD, Chua CC, Cui H, DiPasquale AG, Friedman LS, Heise C, Koeppen H, Kotey A, Mintzer R, Oh A, Roberts DA, et al. Back pocket flexibility provides group II p21-activated kinase (PAK) selectivity for type I 1/2 kinase inhibitors. Journal of medicinal chemistry. 2014; 57:1033-1045. 
32. Ong CC, Gierke S, Pitt C, Sagolla M, Cheng CK, Zhou W, Jubb AM, Strickland L, Schmidt M, Duron SG, Campbell DA, Zheng W, Dehdashti S, Shen M, Yang N, Behnke ML, et al. Small molecule inhibition of group I p21-activated kinases in breast cancer induces apoptosis and potentiates the activity of microtubule stabilizing agents. Breast cancer research : BCR. 2015; 17:59.

33. Curtis C, Shah SP, Chin SF, Turashvili G, Rueda OM, Dunning MJ, Speed D, Lynch AG, Samarajiwa S, Yuan Y, Graf S, Ha G, Haffari G, Bashashati A, Russell R, McKinney S, et al. The genomic and transcriptomic architecture of 2,000 breast tumours reveals novel subgroups. Nature. 2012; 486:346-352.

34. Gyorffy B, Lanczky A, Eklund AC, Denkert C, Budczies J, Li Q and Szallasi Z. An online survival analysis tool to rapidly assess the effect of 22,277 genes on breast cancer prognosis using microarray data of 1,809 patients. Breast cancer research and treatment. 2010; 123:725-731.

35. Jordan VC. Tamoxifen: too much of a good thing? Journal of clinical oncology : official journal of the American Society of Clinical Oncology. 1999; 17:2629-2630.

36. Zhang J, Wang J, Guo Q, Wang Y, Zhou Y, Peng H, Cheng M, Zhao D and Li F. LCH-7749944, a novel and potent p21-activated kinase 4 inhibitor, suppresses proliferation and invasion in human gastric cancer cells. Cancer letters. 2012; 317:24-32.

37. Brunner N, Frandsen TL, Holst-Hansen C, Bei M, Thompson EW, Wakeling AE, Lippman ME and Clarke R. MCF7/LCC2: a 4-hydroxytamoxifen resistant human breast cancer variant that retains sensitivity to the steroidal antiestrogen ICI 182,780. Cancer research. 1993; 53:3229-3232.

38. Johansson HJ, Sanchez BC, Mundt F, Forshed J, Kovacs A, Panizza E, Hultin-Rosenberg L, Lundgren B, Martens U, Mathe G, Yakhini Z, Helou K, Krawiec K, Kanter L, Hjerpe A, Stal O, et al. Retinoic acid receptor alpha is associated with tamoxifen resistance in breast cancer. Nature communications. 2013; 4:2175.

39. Borras M, Hardy L, Lempereur F, el Khissiin AH, Legros N, Gol-Winkler R and Leclercq G. Estradiol-induced downregulation of estrogen receptor. Effect of various modulators of protein synthesis and expression. The Journal of steroid biochemistry and molecular biology. 1994; 48:325-336.

40. Hurtado A, Holmes KA, Ross-Innes CS, Schmidt D and Carroll JS. FOXA1 is a key determinant of estrogen receptor function and endocrine response. Nature genetics. 2011; 43:27-33.

41. Carroll JS, Meyer CA, Song J, Li W, Geistlinger TR, Eeckhoute J, Brodsky AS, Keeton EK, Fertuck KC, Hall GF, Wang Q, Bekiranov S, Sementchenko V, Fox EA, Silver PA, Gingeras TR, et al. Genome-wide analysis of estrogen receptor binding sites. Nature genetics. 2006; 38:1289-1297.

42. Lin CY, Vega VB, Thomsen JS, Zhang T, Kong SL, Xie M, Chiu KP, Lipovich L, Barnett DH, Stossi F, Yeo A, George J, Kuznetsov VA, Lee YK, Charn TH, Palanisamy N, et al. Whole-genome cartography of estrogen receptor alpha binding sites. PLoS genetics. 2007; 3:e87.

43. Castles CG, Oesterreich S, Hansen R and Fuqua SA. Autoregulation of the estrogen receptor promoter. The Journal of steroid biochemistry and molecular biology. 1997; 62(2-3):155-163.

44. Hornbeck PV, Zhang B, Murray B, Kornhauser JM, Latham V and Skrzypek E. PhosphoSitePlus, 2014: mutations, PTMs and recalibrations. Nucleic acids research. 2015; 43(Database issue):D512-520.

45. Chang M. Tamoxifen resistance in breast cancer. Biomolecules \& therapeutics. 2012; 20:256-267.

46. Osborne CK and Schiff R. Mechanisms of endocrine resistance in breast cancer. Annual review of medicine. 2011; 62:233-247.

47. Michalides R, Griekspoor A, Balkenende A, Verwoerd D, Janssen L, Jalink K, Floore A, Velds A, van't Veer L and Neefjes J. Tamoxifen resistance by a conformational arrest of the estrogen receptor alpha after PKA activation in breast cancer. Cancer cell. 2004; 5:597-605.

48. Zwart W, Griekspoor A, Berno V, Lakeman K, Jalink K, Mancini M, Neefjes J and Michalides R. PKA-induced resistance to tamoxifen is associated with an altered orientation of ERalpha towards co-activator SRC-1. The EMBO journal. 2007; 26:3534-3544.

49. Holm C, Kok M, Michalides R, Fles R, Koornstra RH, Wesseling J, Hauptmann M, Neefjes J, Peterse JL, Stal O, Landberg G and Linn SC. Phosphorylation of the oestrogen receptor alpha at serine 305 and prediction of tamoxifen resistance in breast cancer. The Journal of pathology. 2009; 217:372-379.

50. Wang RA, Mazumdar A, Vadlamudi RK and Kumar R. P21-activated kinase-1 phosphorylates and transactivates estrogen receptor-alpha and promotes hyperplasia in mammary epithelium. The EMBO journal. 2002; 21:5437-5447.

51. de Leeuw R, Flach K, Bentin Toaldo C, Alexi X, Canisius S, Neefjes J, Michalides R and Zwart W. PKA phosphorylation redirects ERalpha to promoters of a unique gene set to induce tamoxifen resistance. Oncogene. 2013; 32:3543-3551.

52. Rane CK and Minden A. P21 activated kinases: structure, regulation, and functions. Small GTPases. 2014; 5:e28003.

53. Ha BH, Morse EM, Turk BE and Boggon TJ. Signaling, Regulation, and Specificity of the Type II p21-activated Kinases. The Journal of biological chemistry. 2015; 290:12975-12983.

54. Zhu J, Zhao C, Kharman-Biz A, Zhuang T, Jonsson P, Liang N, Williams C, Lin CY, Qiao Y, Zendehdel K, Stromblad S, Treuter E and Dahlman-Wright K. The atypical ubiquitin ligase RNF31 stabilizes estrogen receptor alpha and modulates estrogen-stimulated breast cancer cell proliferation. Oncogene. 2014; 33:4340-4351.

55. Qiao Y, Shiue CN, Zhu J, Zhuang T, Jonsson P, Wright AP, Zhao C and Dahlman-Wright K. AP-1-mediated chromatin looping regulates $\mathrm{ZEB} 2$ transcription: new insights into 
TNFalpha-induced epithelial-mesenchymal transition in triple-negative breast cancer. Oncotarget. 2015; 6:7804-7814.

56. Matthews J, Wihlen B, Tujague M, Wan J, Strom A and Gustafsson JA. Estrogen receptor (ER) beta modulates ERalpha-mediated transcriptional activation by altering the recruitment of c-Fos and c-Jun to estrogenresponsive promoters. Molecular endocrinology. 2006; 20:534-543.
57. Zhu J, Zhao C, Zhuang T, Jonsson P, Sinha I, Williams $\mathrm{C}$, Stromblad S and Dahlman-Wright K. RING finger protein 31 promotes p53 degradation in breast cancer cells. Oncogene. Advance online publication 6 July 2015; doi: 10.1038/onc.2015.260.

58. Li Q, Birkbak NJ, Gyorffy B, Szallasi Z and Eklund AC. Jetset: selecting the optimal microarray probe set to represent a gene. BMC bioinformatics. 2011; 12:474. 